\title{
Histoplasmosis progresiva diseminada en un paciente sin VIH
}

\section{Progressive disseminated histoplasmosis in a HIV-free patient}

Palabras clave: histoplasma, histoplasmosis, histoplasmosis progresiva diseminada, aspectos clínicos.
Key words: histoplasma histoplasmosis progressive

disseminated histopasmosis, clinical aspects.
Hernán Isaías Vargas Plazas ${ }^{1}$, Rina Liliana Luna Tavera ${ }^{2}$, Víctor Manuel Molano Trujillo ${ }^{3}$, Diego Fernando Salinas Cortés ${ }^{4}$

\section{Resumen}

Objetivo: reportar un caso de histoplasmosis progresiva diseminada en un paciente sin inmunodeficiencia, con Elisa para VIH negativo y discusión con respecto a la presentación clínica y diagnóstico. Diseño del estudio: reporte de un caso clínico y revisión de la literatura. Métodos: historia clínica, histopatología, reporte de paraclínicos, revisión de artículos publicados en revistas indexadas. Resultados: el paciente presenta síntomas de 1 mes de duración con pérdida de peso, hemoptisis, disfagia progresiva, lesiones en piel y mucosas ulceradas. En las biopsias tomadas se identificaron blastoconidias intracelulares y levaduras en los tejidos de ganglio, mucosa gástrica y médula ósea. Conclusiones: es un caso de histoplamasmosis progresiva en paciente sin VIH con compromiso pulmonar, gástrico y tejido linfático.

\begin{abstract}
Objective: To report a case of progressive disseminated histoplasmosis in a patient without immunodeficiency, HIV Elisa negative and discussion regarding the clinical presentation and diagnosis. Study design: Clinical case report and literature review. Methods: medical history, histopathology, paraclinics' report, review of articles published in indexed journals. Results: The patient has 1-month length symptoms: weight loss, hemoptysis, progressive dysphagia, skin lesions and ulcerated mucosa. In biopsies taken, intracellular blastoconidias and yeast were identified in lymph tissues, gastric mucosa and bone marrow. Conclusions: It is a case of progressive histoplamasmosis in HIV-free patients with lung, gastric and lymphatic tissue involvement.
\end{abstract}

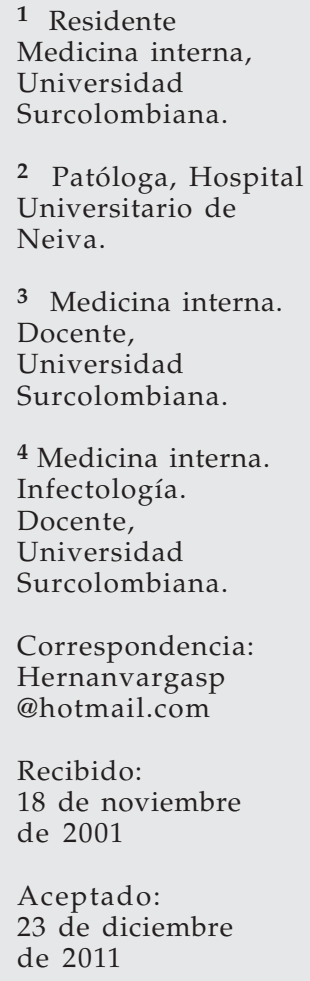

Correspondencia:

Hernanvargasp

@hotmail.com

Recibido:

18 de noviembre de 2001

Aceptado: 23 de diciembre de 2011

\section{Introducción}

El Histoplasma capsulatum fue reportado por primera vez en 1905 por Samuel Darling un médico patólogo que describió los hallazgos post mortem de un paciente con esplenomegalia, emaciación, fiebre, leucemia y anemia; encontrando invasión de las células endoteliales en ganglios linfáticos por pequeños microorganismos encapsulados ${ }^{(1)}$.

El Histoplasma capsulatum es el agente causal de la histoplasmosis, una de las micosis sistémicas más comunes en el mundo ${ }^{(2)}$. Es endémica en las américas incluyendo el territorio colombiano(3). El Grupo de Microbiología del Instituto Nacional de Salud de 
Colombia y el Grupo de Micología del Centro de Investigaciones Biomédicas, en su encuesta Nacional registró 434 pacientes con histoplasmosis, la mitad de los casos informados correspondieron al Departamento de Antioquia, seguido por el Distrito de Bogotá luego Cundinamarca, Boyacá, Valle del Cauca, Santander y Caldas ${ }^{(14)}$. Es un hongo dimórfico que cambia de micelio a levadura de acuerdo a la temperatura. En el suelo y en cultivos a temperatura inferiores a $35^{\circ} \mathrm{C}$ se encuentra como moho provisto de micelios septados que dan lugar a microconidias $(2-5 \mu \mathrm{m})$ y macroconidias (8$15 \mu \mathrm{m})$ las cuales son asexuadas, en cultivos superiores a $37^{\circ} \mathrm{C}$ y en tejidos humanos se comporta como levadura $(2-4 \mu \mathrm{m})$ uninucleada que se reproduce por gemación simple ${ }^{(2,4)}$. El hábitat de $H$. capsulatum lo constituyen los suelos enriquecidos con nitrógeno orgánico, suministrado por excrementos de aves y de murciélagos, por lo que los lugares en los que ocurre acumulación de este material constituyen importantes fuentes de infeccin ${ }^{(5)}$.

Existen dos variedades de Histoplasma capsulatum que son patógenas para el humano el Histoplasma capsulatum variedad capsulatum que es el agente causal de la histoplasmosis clásica y el Histoplasma capsulatum variedad duboisii que produce la histoplasmosis africana y solamente esta descrita en este continente. La forma sexuada del histoplasma se denomina Ajellomyces capsulatum(2).

La infección se adquiere por la inhalación de las conidias que son las partículas infectantes, la mayoría de los casos se presenta como una enfermedad similar a la influenza que se autolimita y solo requiere manejo sintomático en pacientes con estado inmunológico normal y bajo inoculo. Aproximadamente 5\% de los pacientes infectados experimentan progresión extrapulmonar que amenaza la vida sin tratamiento oportuno ${ }^{(6)}$.

Los factores predisponentes para la progresión sintomática de la histoplasmosis están dados por la edad siendo más importante en los extremos de la vida, enfermedades oncológicas tipo leucemias y linfomas, inmunosupresión iatrogénica y deficiencia congénita de linfocitos $T$, actualmente la infección por VIH ha generado mayor número de casos especialmente con recuentos de CD4 inferiores a $200 \mathrm{cel} / \mu \mathrm{L}^{(4,7)}$. La histoplasmosis se presenta como riesgo ocupacional relacionado con el mayor tamaño del inoculo en trabajos relacionados con remoción de tierra en áreas endémicas: colectores de guano, arqueólogos, agricultores, espeleólogos, mineros, antropólogos etc ${ }^{(8)}$.

La histoplasmosis se presenta en varias formas clínicas que dependen del tamaño del inóculo y el estado inmunitario de la persona, se describe en aguda primaria, pulmonar aguda, diseminada progresiva (aguda y crónica), pulmonar crónica y formas residuales (Tabla 1$)^{(4,8)}$.

La histoplasmosis diseminada comprende el espectro más severo de todas las formas clínicas de la enfermedad, involucra invasión de más de dos órganos por el histoplasma, la diseminación puede ocurrir a partir del foco pulmonar primario o por reactivación endógena de un foco latente. Esta caracterizada por la intensa fagocitosis del hongo por los macrófagos y ocurre compromiso severo de los órganos. Representa un fracaso en la contención de la invasión dado por falla en la inmunidad o por alto inoculo infectante que desborda la capacidad de la respuesta inmune ${ }^{(4,7,13)}$.

\section{Reporte del caso}

Paciente masculino de 39 años de edad, procedente de la Plata, Huila, agricultor de ocupación. Sin antecedentes previos de enfermedad ni alergias conocidas, que ingresa por historia de un mes de tos con expectoración purulenta, ocasionalmente hemoptoica, asociado a disfagia de sólidos y luego a los líquidos con emesis post prandial, y pérdida de peso de 10 kilos en el último mes. Además manifiesta astenia y dinamia que se han aumentado su intensidad en las semanas anteriores. Ingresa con taquicardia pero estable hemodinámicamente, aspecto general caquéctico, escleras ictéricas, palidez mucocutánea. Úlcera en paladar de $3 \times 4 \mathrm{~cm}$ de base granulomatosa, 
Tabla 1. Histoplasmosis. Características de las formas clínicas.

\begin{tabular}{|c|c|c|c|c|c|c|}
\hline \multicolumn{2}{|c|}{ Forma clínica } & Exposición & Síntomas & $\begin{array}{l}\text { Compromiso } \\
\text { pulmonar }\end{array}$ & $\begin{array}{l}\text { Compromiso de } \\
\text { otros órganos }\end{array}$ & $\begin{array}{c}\text { Factores } \\
\text { predisponentes }\end{array}$ \\
\hline \multirow{2}{*}{$\underbrace{\frac{\pi}{4}}_{\substack{0\\
}}$} & 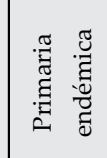 & \multirow{2}{*}{$\begin{array}{l}\text { Actividades } \\
\text { creadores } \\
\text { de aerosoles, } \\
\text { muchas } \\
\text { veces } \\
\text { conocidas. }\end{array}$} & $\begin{array}{l}\text { Similar a la } \\
\text { influenza, } \\
\text { autolimitada. }\end{array}$ & $\begin{array}{l}\text { No aparente, } \\
\text { calcificaciones en } \\
\text { perdigones. }\end{array}$ & $\begin{array}{l}\text { Lesiones calcificadas en } \\
\text { bazo e hígado tiempo } \\
\text { después de la primo } \\
\text { infección. }\end{array}$ & $\begin{array}{l}\text { Exposición } \\
\text { ocupacional. }\end{array}$ \\
\hline & 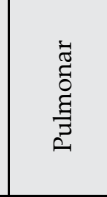 & & $\begin{array}{l}\text { Fiebre, malestar, } \\
\text { debilidad. } \\
\text { Disconfort } \\
\text { torácico, tos } \\
\text { seca. }\end{array}$ & $\begin{array}{l}\text { Rx tórax infiltrados, } \\
\text { reticonodular o } \\
\text { miliares, adenopatías } \\
\text { hiliares. calcificación } \\
\text { residual. }\end{array}$ & $\begin{array}{l}\text { Eritema nodoso, eritema } \\
\text { multiforme. Artritis } \\
\text { simétrica poliarticular } \\
(<5 \%) \text {, pericarditis en } \\
\text { raza negra. }\end{array}$ & $\begin{array}{l}\text { Ocupacional, edad, } \\
\text { inmunodepresión } \\
\text { (particularmente } \\
\text { en presentaciones } \\
\text { severas). }\end{array}$ \\
\hline \multirow{2}{*}{ 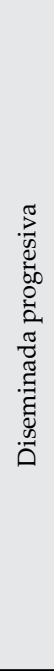 } & $\frac{\pi}{3}$ & $\begin{array}{l}\text { Primo } \\
\text { infección o } \\
\text { reactivación. }\end{array}$ & $\begin{array}{l}\text { Fiebre, pérdida } \\
\text { de peso, diarrea, } \\
\text { sepsis. }\end{array}$ & $\begin{array}{l}\text { Tos, Rx tórax, } \\
\text { infiltrado } \\
\text { reticulonodular } \\
\text { o normal. }\end{array}$ & $\begin{array}{l}\text { Hepatomegalia, } \\
\text { esplenomegalia, } \\
\text { linfadenopatias, } \\
\text { pancitopenia, PCR, VSG, } \\
\text { LDH y ferritina } \\
\text { aumentada. CID, falla } \\
\text { renal y SDRA. }\end{array}$ & $\begin{array}{l}\text { VIH, receptor } \\
\text { de transplante, } \\
\text { malignidad } \\
\text { hematológica } \\
\text { y uso esteroides y } \\
\text { biológicos, neonatos. }\end{array}$ \\
\hline & 芯 & $\begin{array}{l}\text { No } \\
\text { reconocida } \\
\text { con } \\
\text { precisión. } \\
\text { Reactivación } \\
\text {. }\end{array}$ & $\begin{array}{l}\text { Fiebre } \\
\text { esporádica, } \\
\text { malestar } \\
\text { general, } \\
\text { anorexia. }\end{array}$ & $\begin{array}{l}\text { Tos, Rx tórax, } \\
\text { infiltrado } \\
\text { reticulonodular o } \\
\text { normal. }\end{array}$ & $\begin{array}{l}\text { Igual que en la forma } \\
\text { aguda, úlceras } \\
\text { orofaríngeas y gastro- } \\
\text { intestinales. En piel } \\
\text { lesiones papulares- } \\
\text { nodulares y ulceradas. } \\
\text { Infiltración glándulas } \\
\text { adrenales, endocarditis } \\
\text { y meningitis basilar } \\
\text { crónica. }\end{array}$ & $\begin{array}{l}\text { Sin } \\
\text { inmunodepresión } \\
\text { demostrable, } \\
\text { ancianos, gran } \\
\text { tamaño del inóculo, } \\
\text { alcoholismo. }\end{array}$ \\
\hline & 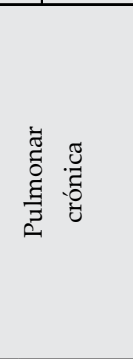 & $\begin{array}{l}\text { No suele ser } \\
\text { reconocida. }\end{array}$ & $\begin{array}{l}\text { Deterioro estado } \\
\text { general, dolor } \\
\text { torácico, tos } \\
\text { productiva, } \\
\text { hemoptisis. } \\
\text { Sudoración } \\
\text { nocturna, } \\
\text { anorexia, } \\
\text { pérdida de peso. }\end{array}$ & $\begin{array}{l}\text { Insuficiencia } \\
\text { respiratoria } \\
\text { progresiva, lesiones } \\
\text { necróticas con } \\
\text { formación de } \\
\text { cavernas, compromiso } \\
\text { apical posterior, } \\
\text { fibrosis. }\end{array}$ & Restringida al pulmón. & $\begin{array}{l}\text { Enfisema, EPOC, } \\
\text { problemas } \\
\text { estructurales del } \\
\text { pulmón. }\end{array}$ \\
\hline \multirow{3}{*}{ 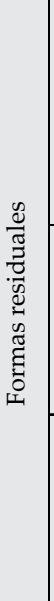 } & 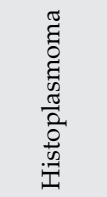 & $\begin{array}{l}\text { No } \\
\text { reconocida. }\end{array}$ & $\begin{array}{l}\text { Asintomático, } \\
\text { aumento de } \\
\text { tamaño de la } \\
\text { lesión. }\end{array}$ & $\begin{array}{l}\text { Rx tórax, lesión } \\
\text { aspecto nodular } \\
\text { periférico calcificado, } \\
\text { aspecto bulbo de } \\
\text { cebolla. }\end{array}$ & Restringida al pulmón. & Desconocido. \\
\hline & 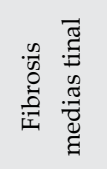 & $\begin{array}{l}\text { No } \\
\text { reconocida. }\end{array}$ & $\begin{array}{l}\text { Disnea, tos, } \\
\text { hemoptisis } \\
\text { sÍndrome vena } \\
\text { cava superior. }\end{array}$ & $\begin{array}{l}\text { Rx, mediastino } \\
\text { ensanchado. }\end{array}$ & $\begin{array}{l}\text { Vena cava, esófago, } \\
\text { nervio laríngeo } \\
\text { recurrente, arteria y } \\
\text { vena pulmonar. }\end{array}$ & $\begin{array}{l}\text { Edad } 20-40 \text { años, } \\
\text { mujer. }\end{array}$ \\
\hline & 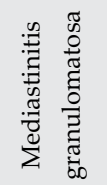 & $\begin{array}{l}\text { No } \\
\text { reconocida. }\end{array}$ & $\begin{array}{l}\text { Usualmente } \\
\text { asintomático. }\end{array}$ & $\begin{array}{l}\text { Rx ensanchamiento } \\
\text { hiliar, subcarinal y } \\
\text { paratraqueal. }\end{array}$ & $\begin{array}{l}\text { Compresión de } \\
\text { estructuras bronquiales, } \\
\text { vasculares y esófago. }\end{array}$ & Desconocido. \\
\hline
\end{tabular}

Adaptado de la tabla 28-1, Ángela Restrepo. Histoplasmosis. Fundamentos de Medicina. Enfermedades infecciosas. 6. ${ }^{\mathrm{a}}$ edición, CIB, pág. 316.(4) 
lesiones blanquecinas algodonosas en lengua y boca (Figura 1A). Ganglios palpables submandibulares, cervicales y axilares bilaterales. Presenta nódulos en la piel de tamaños variables que no superan $\operatorname{los} 5 \mathrm{~cm}$, eritematosos, de color violáceo, doloroso a la palpación, uno de ellos en la cara anterior del tórax ulcerado de bordes irregulares no elevado sin secreción en su interior (Figura 1B). Al ingreso la formula hemática demuestra anemia normocítica, normocrómica y resto de paraclínicos normales (Tabla 2). En la radiografía simple de tórax se encuentran opacidades de ocupación alveolar confluentes en tórax izquierdo y agrandamiento del hilio izquierdo. Al compararlo con la tomografía de tórax de alta resolución se encuentra horizontalización y dilatación del bronquio fuente izquierdo con lesiones hiperdensas peribronquiales e irregularidades en su lumen (Figura 2). En la endoscopia se logra ver

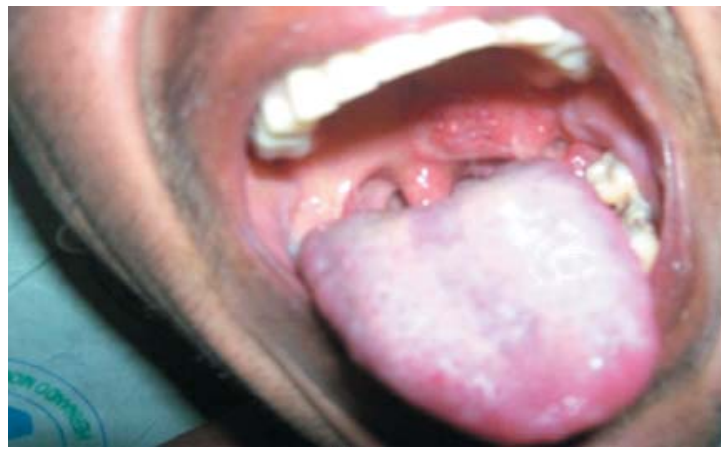

Figura 1 A. Úlcera en paladar blando aspecto granulomatoso con bordes definidos indurados.

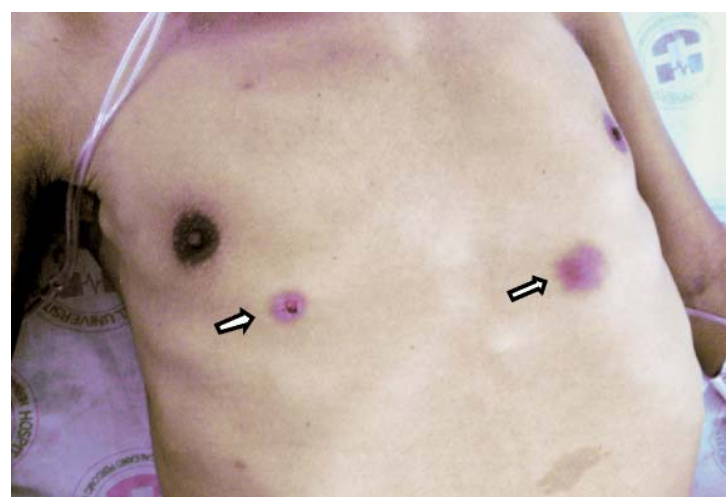

Figura B. Nódulos subcutáneos en cara anterior de tórax duros, violáceos con úlcera en su parte central (flecha).
Tabla 2. Resultados paraclínicos.

\begin{tabular}{lcc}
\hline Laboratorio & Resultado & Unidad \\
\hline $\begin{array}{l}\text { Cuadro hemático, } \\
\text { leucocitos }\end{array}$ & 3600 & $\mathrm{cel} / \mathrm{mm} 3$ \\
\hline Neutrófilos & 84 & $\%$ \\
\hline Linfocitos & 13 & $\%$ \\
Hemoglobina & 6,7 & $\mathrm{gr} / \mathrm{dl}$ \\
Hematocrito & 22 & $\%$ \\
VCM & 86 & $\mathrm{fL}$ \\
HCM & 27,1 & $\mathrm{pg}$ \\
\hline Bilirrubina total & 1,63 & $\mathrm{md} / \mathrm{dl}$ \\
Bilirrubina indirecta & 1,18 & $\mathrm{mg} / \mathrm{dl}$ \\
Elisa VIH 1 y 2 & no reactivo & - \\
\hline Baciloscopia núm. 3 & negativo & - \\
\hline Creatinina & 0,91 & $\mathrm{mg} / \mathrm{dl}$ \\
Nitrógeno ureico & 21 & $\mathrm{mg} / \mathrm{dl}$ \\
AST ${ }^{+}$ & 19 & $\mathrm{mg} / \mathrm{dl}$ \\
\hline ALT ${ }^{++}$ & 23 & $\mathrm{mg} / \mathrm{dl}$ \\
\hline & &
\end{tabular}

* VCM: volumen corpuscupular medio.

** HCM: hemoglobina corpuscular media.

† AST: aspartato aminotransferasa.

†† ALT: alanina aminotransferasa.

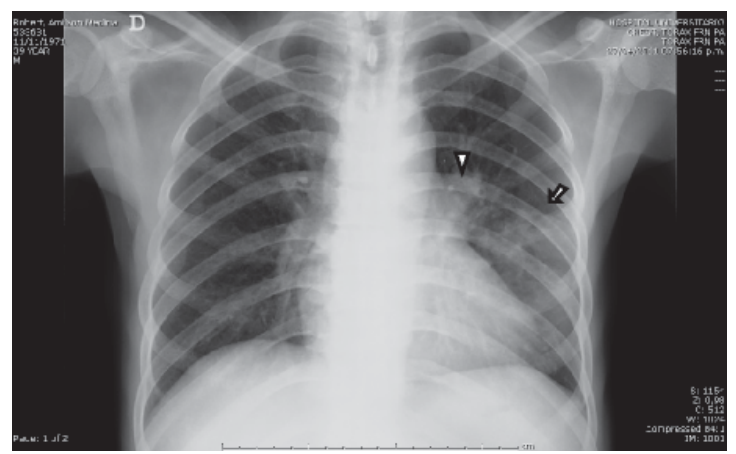

Figura 2A. Radiografía de tórax: infiltrado alveolar en hemotorax izquirdo (flecha) y opacidad en hilio derecho (punta de flecha).

esofagitis candidiásica, divertículo esofágico y en duodeno dos lesiones elevadas de centro deprimido que se toman biopsias (Figura 3A). Se toma aspirado y biopsia de médula ósea (Figura 3B), biopsia de lesión ulcerosa en boca (Figura 3C) y biopsia de ganglio cervical (Figura 3D). Para las biopsias de los tejidos de ganglio cervical, úlcera en paladar y duodenal y aspirado de médula ósea se utilizó las tinciones de 


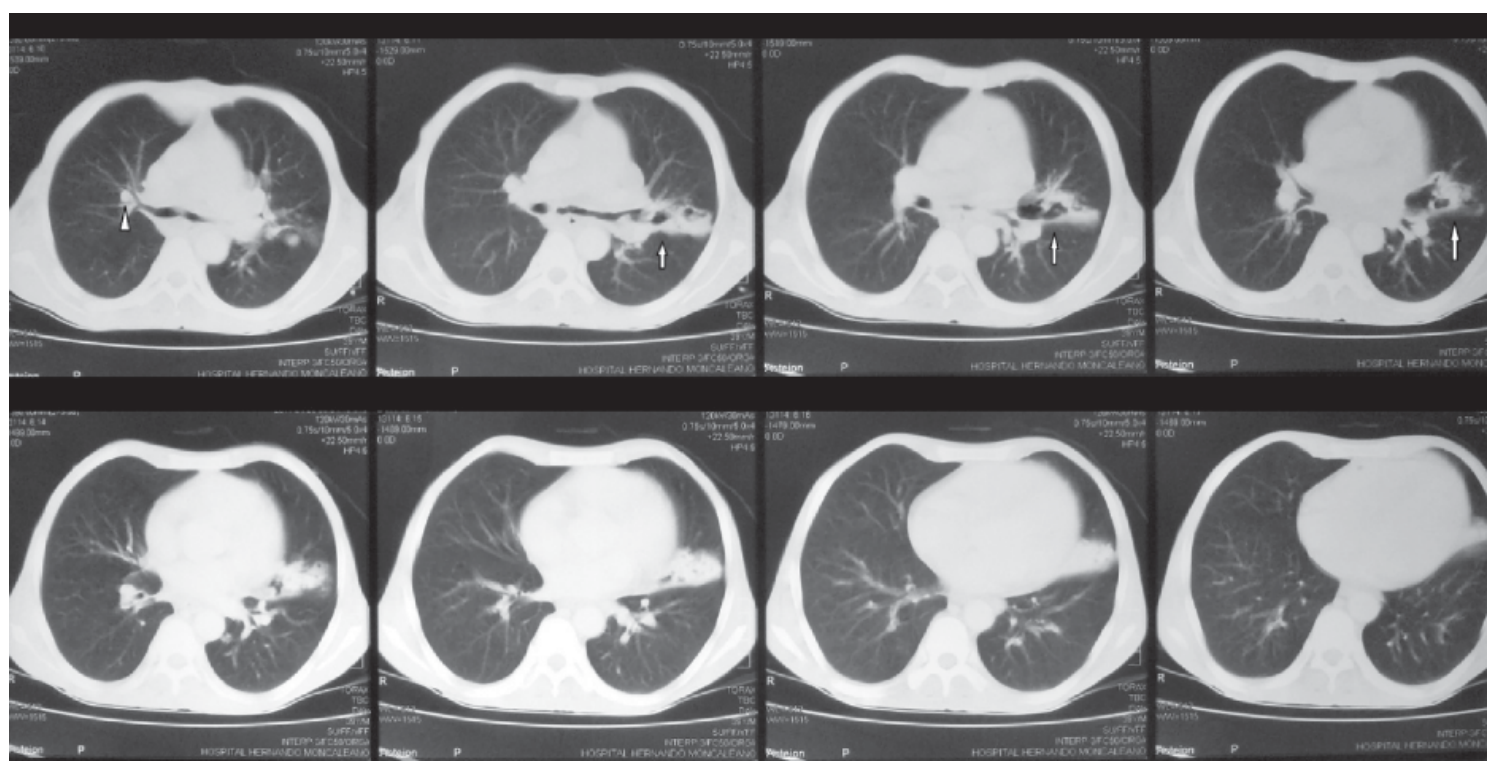

Figura 2B. Tomografía de tórax: dilatación del bronquio fuente izquierdo con infiltrado de ocupación alveolar perihiliar y peribronquial (flecha), con nódulo de $1 \mathrm{~cm}$ peribronquial derecho (punta de flecha).

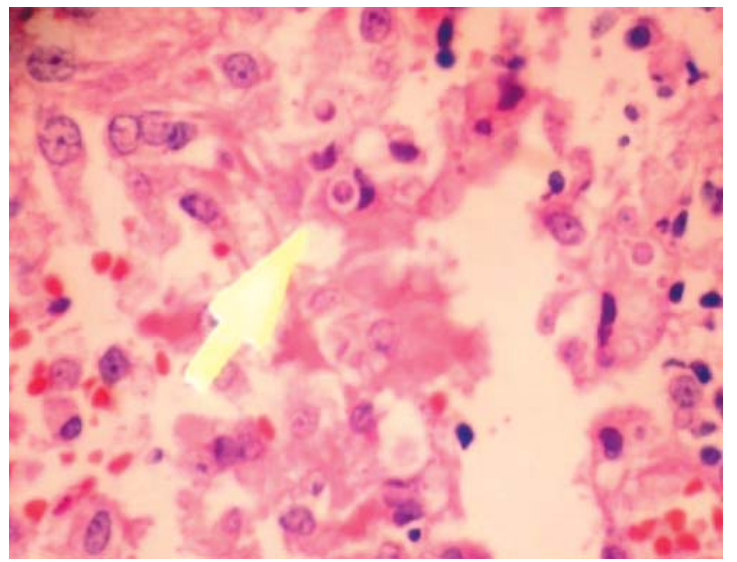

Figura 3A. Biopsia de úlcera duodenal con tinción hematoxilina-eosina. Se observa levadura extracelular del histoplasma capsulatum (flecha).

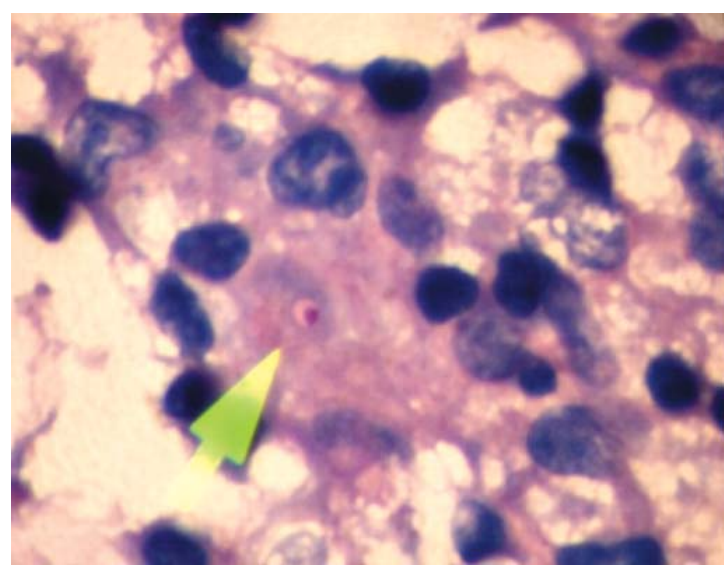

Figura 3 B. Extendido de médula ósea con tinción de Ziehl-Neelsen se una Blastoconidia intracelular (flecha).

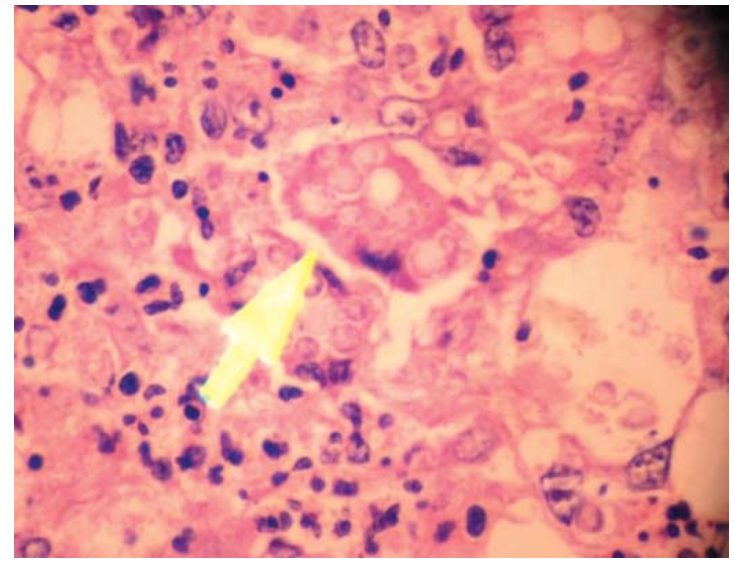

Figura 3 C. Biopsia de ganglio cervical con tinción hematoxilina-eosina. Se observa un histiocito con múltiples blastoconidias intracelulares (flecha).

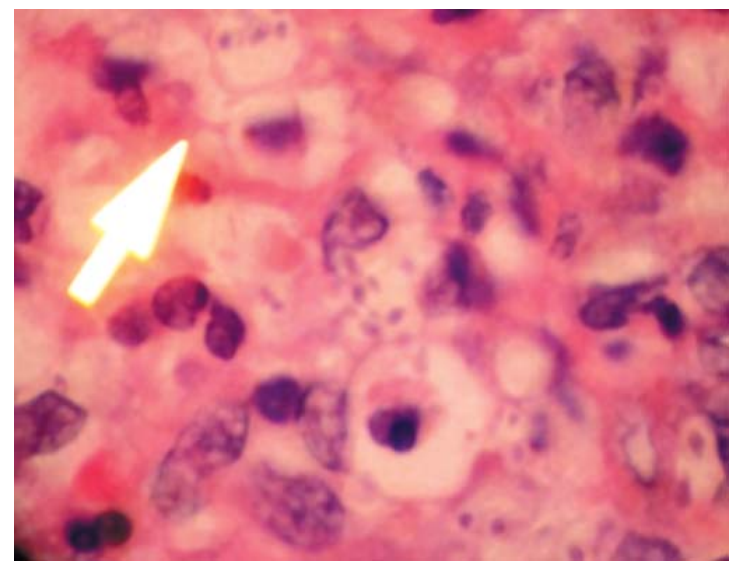

Figura 3 D. Biopsia de úlcera de paladar con tinción hematoxilina-eosina. Se observa múltiples Blastoconidias intracelulares. 
hematoxilina-eosina y ziehl neelsen donde se documentó la presencia de áreas necróticas con infiltrado inflamatorio crónico linfohistoplasmocitario e histiocitos epiteloides con formación de granulomas y células gigantes multinucleadas, se encuentran numerosas formas de levaduras grandes de doble contorno birrefringentes y glóbulo eosinofílico en el centro compatibles con histoplasmosis. El paciente durante la hospitalización presenta deterioro clínico, presentando un episodio de hemoptisis de aproximadamente 1000 cc de sangre rutilante, con compromiso hemodinámico y ventilatorio. Requiere intubación orotraqueal. Se realiza fibrobroncoscopia para control del sangrado encontrando sangre en vía aérea, engrosamiento y granulación de árbol bronquial con fístula subcarinal en bronquio fuente izquierdo que se controla con intubación selectiva de bronquio derecho y enclavación de catéter fogarthy en el sitio de la fístula, el paciente permanece en la unidad de cuidados intensivos. Finalmente fallece a las 72 horas. Dado la complicación temprana de la hemoptisis masiva que sufre el paciente durante la hospitalización y que le ocasiona la muerte y ante la ausencia de certeza de la etiología que explique el cuadro clínico no administra terapia específica para la histoplasmosis. No se documentó presencia de células sugestivas de malignidad o de otros microorganismos causantes de enfermedades granulomatosas en los cortes de las muestras de los tejidos biopsiados.

\section{Discusión}

La histoplasmosis diseminada es una enfermedad con múltiples presentaciones clínicas y por consiguiente no siempre es fácil establecer el diagnóstico con certeza. La fiebre es el síntoma más común acompañado de pérdida de peso y viceromegalia ${ }^{(4,8)}$. En pacientes con VIH el síntoma más común fue la fiebre en el $95 \%$ de los casos y la tos en el $61 \%$ de los casos, solo el $9 \%$ presenta exposición ocupacional de riesgo. Los reactantes de fase aguda (PCR, VSG, ferritina) están elevados en pacientes inmunocompetentes, como en inmunocomprometidos (VIH por ej.), siendo un hallazgo inespecífico para el diagnóstico; se han descrito niveles más elevados de estos marcadores en pacientes con VIH comparados con pacientes sin esta enfermedad(13). Los niveles elevados de LDH más de dos veces el valor normal superior, se asoció a mayor riesgo de mortalidad en pacientes con VIH (RR: 5,2 IC 95\% 1,2-22) ${ }^{(5,9)}$. Se puede encontrar hipercalcemia como ocurre con otras enfermedades granulomatosas y muchas manifestaciones clínicas se pueden confundir con sarcoidosis ${ }^{(7)}$.

En el caso presentado se trata de un paciente sin evidencia de inmunodeficiencia adquirida con un conjunto de síntomas principales dado por fiebre, pérdida de peso, linfadenopatía, tos purulenta los cuales están presentes en otras patologías como tuberculosis, procesos neoplásicos, enfermedades granulomatosas y otras enfermedades infecciosas crónicas ${ }^{(4)}$. La histoplasmosis diseminada se presenta en 1 de cada 2000 casos en pacientes en áreas endémicas y con inmunidad conservada mientras que en pacientes con infección por VIH con recuento de linfocitos CD4+ menor a 100/ $\mu 1$ la forma diseminada representa el $50 \%$ del total de los $\operatorname{casos}^{(9)}$.

Las lesiones ulceradas presentes en la mucosa orofaríngea son la resultante de diseminación hematogena siendo más frecuentes en la histoplasmosis diseminada que en otras micosis profundas a excepción de la paracoccidioidomicosis. ${ }^{(7)}$ Debe establecerse diagnóstico diferencial con úlceras traumáticas, carcinoma escamo-celular, linfoma, gingivitis-estomatitis necrótica ulcerativa $^{(6)}$.

Dentro de las manifestaciones cutáneas frecuentemente descritas, se encuentra el eritema nodoso y el eritema migratorio. El paciente exhibía dos lesiones compatibles con eritema nodoso en región anterior del tórax ${ }^{(7)}$, sin embargo hay que plantear la posibilidad de otras entidades que expresen esta misma lesión como son infecciones estreptococcicas, sarcoidosis, coccidioidomicosis, tuberculosis, brucelosis, e infecciones por clamidias ${ }^{(11)}$. El compromiso en la piel es más frecuente en pacientes con histoplasmosis diseminada, especialmente 
en coinfectados con VIH cuya presentación corresponde al 53\% de los casos comparado con $9 \%$ en pacientes sin VIH $(\mathrm{P}<0,01)$. Las lesiones en pacientes sin VIH son más circunscritas comparadas con los pacientes que padecen VIH que tienden a ser más dispersas y polimorfas ${ }^{(13)}$.

El compromiso en el tracto gastrointestinal es común en la forma diseminada de la histoplasmosis pero no es usualmente sintomática, puede presentarse diarrea, dolor abdominal y náuseas. La lesión macroscópica más frecuente es la ulceración de la mucosa, siendo el sitio más frecuentemente afectado el íleon terminal. Es frecuente encontrar infiltración del histoplasma en los estudios de autopsias de pacientes fallecidos. Se han presentados casos con perforación intestinal en ciego y colon, peritonitis y obstrucción intestinal ${ }^{(7,8)}$. En este caso reportado encontramos evidencia endoscópica de una lesión en duodeno ulcerada y además con compromiso esofágico.

Aunque el compromiso pulmonar y orofaríngeo es frecuente, hay poca evidencia de invasión bronquial, en este caso se observó en la fibrobroncoscopia engrosamiento y granulación de todo el árbol bronquial con fístula y sangrado activo, correlacionado bien con los hallazgos vistos en la tomografía computarizada de tórax que evidenciaron en el bronquio fuente izquierdo dilatación post obstructiva e irregularidad en la luz bronquial. La mayoría de los pacientes con histoplasmosis diseminada no tienen compromiso traqueal ni bronquial o el compromiso está dado por compresión extrínseca por granulomas o fibrosis. Otras manifestaciones bronquiales son la inflamación crónica o aguda, secreción mucopurulenta, friabilidad y ulceración $^{(10)}$.

La hemoptisis en pacientes con histoplasmosis diseminada es la resultante del compromiso inflamatorio bronquial. En nuestro medio la hemoptisis es causada más frecuentemente por otras enfermedades como la tuberculosis, carcinoma broncogénico y menos frecuente causas sistémicas. La presentación de hemoptisis masiva por lesión directa del histoplasma en el bronquio no es frecuente ${ }^{(10,12)}$.
La histoplasmosis se puede diagnosticar por métodos microbiológicos directos como la biopsia que emplean una variedad de coloraciones especiales tales como Wright, Giemsa y plata metenamina y por cultivo siendo esta el «gold» estándar. El diagnóstico por métodos indirectos que incluyen la detección de anticuerpos y antígenos ${ }^{(15)}$. La observación microscópica permite visualizar las levaduras intracelulares, localizadas en el citoplasma de macrófagos y células fagocíticas, con una sensibilidad del $50 \%$, con falsos positivos al confundirse con levaduras de candidas spp, Leishmania spp., Pneumocystis jirovecii, Cryptococcus neoformans, Blastomyces dermatitidis. El cultivo con una sensibilidad hasta del $80 \%$ se basa en la identificación de las características macroscópicas y microscópicas de las colonias, el medio de cultivo usualmente utilizado es el agar de infusión de cerebro y corazón $^{(15)}$.

La detección de anticuerpos por fijación del complemento y por Elisa tiene una sensibilidad del $72-94 \%$ y $92 \%$ respectivamente, que es dependiente de la forma clínica y el estado inmunitario, siendo mayor la rentabilidad diagnóstica para los pacientes inmunosupresos y con formas diseminadas ${ }^{(15)}$. La detección de antígenos es una herramienta importante para el diagnóstico temprano en formas diseminadas y seguimiento de pacientes en tratamiento, con una sensibilidad diagnóstica entre $80 \%$ y $95 \%$ para la antigenuria y del $67 \%$ al $86 \%$ para la antigenemia. Para las técnicas moleculares basadas en la reacción en cadena de la polimerasa se ha publicado sensibilidad del $89 \%$ al $100 \%{ }^{(15)}$.

Para el tratamiento de las formas diseminadas agudas clínicamente severas la anfotericina $\mathrm{B}$ es el medicamento de recomendado a dosis de $1 \mathrm{mg} / \mathrm{kg}$ diario por 2 semanas y dosis de 3-5 mg/ kg dia para la presentación liposomal, continuándose con itraconazol oral $200 \mathrm{mg}$ oral tres veces al dia por 12 meses. En las formas diseminadas leves a moderadas se requiere administrar solamente itraconazol. Se recomienda profilaxis secundaria con itraconazol para los pacientes con VIH y conteo de CD4 $<150 \mathrm{cel} / \mu \mathrm{l}^{(16)}$. 


\section{Referencias}

1. Histoplasmosis. Editorial. (1942). J Am Med Assoc. 119(3):265-266. http://jama.amaassn.org/content/119/3/265.extract

2. González A, Múnera M. (2007). Histoplasma capsulatum en microbiología de las infecciones humanas. CIB, 742-750.

3. Kasuga T, White T, Koenig G, Mcewen J, Restrepo A et al. (2003). Phylogeography of the fungal pathogen Histoplasma capsulatum. Molecular ecology, 12:3383-3401. http:/ /nature.berkeley.edu/taylorlab/papers/ kasuga2003a.pdf

4. Restrepo A. Histoplasmosis. (2003). Fundamentos de medicina enfermedades infecciosas. CIB, 316-326.

5. Castañeda E. (2004). Histoplasmosis: nuevos datos colombianos. IX Curso Internacional de Enfermedades Infecciosas. X Seminario Integral del Sida. II Seminario de Medicina Psicosomática y Psiquiatría de Enlace. Santiago de Cali, Colombia, marzo 31 a abril 3. http:/ / www.cls.org.co/uploaded_user / pdf2004/28.pdf

6. Valle A, Moreira L, Almeida-Paes R et al. (2006). Chronic disseminated histoplasmosis with lesions restricted to the mouth: case report. Rev Inst Med trop S. Paulo [online]. 48(2):113-116. http:/ /www.scielo.br/pdf/ rimtsp/v48n2/a12v48n2.pdf

7. Kauffman C. (2007). Histoplasmosis: a Clinical and Laboratory Update. Clin Microbiol Rev 20:115-132. http://cmr.asm.org/ $\mathrm{cgi} / \mathrm{reprint} / 20 / 1 / 115$ ? maxto show $=\&$ hits $=$ 10\&RESULTFORMAT $=\&$ fulltext $=$ histoplas mosis\&searchid $=1 \&$ FIRSTINDEX $=0$ \& resour cetype $=$ HWCIT

8. Vargas M, Estrada M., et al. (2006). Histoplasmosis diseminada. Informe de un caso de autopsia y revisión de la literatura. Revista de la Facultad de Medicina, Núm. 003. http:/ /www.ejournal.unam.mx/rfm/no49-3/ RFM49307.pdf

9. Velázquez G, Rueda Z. (2010). Histoplasmosis en pacientes con SIDA. Un estudio de cohorte en Medellín, Colombia. Infectio, 14(S2):S99-S106. http://www.revistain fectio.org/site/Portals/0/vol_14_s2/4_his toplasmosis_en_sida.pdf

10. Houssein Y, Ross G, Jan VP, Kellie RJ. (2009). Tracheal and Endobronchial Involvement in Disseminated Histoplasmosis: A Case Report Chest, 136(6):1650-1653; doi:10.1378/ chest. 09-0236 http:// chestjournal.chestpubs.org/ content/136/6/1650.full.pdf

11. Bolognia J, Braverman I. Manifestaciones cutáneas de enfermedades internas. Harrison principios de medicina interna 17 edición, 54:332-333.

12. Pinzón T, Lastra G. (2005). Causas de hemoptisis en el Hospital Universitario de Neiva. Revista colombiana de neumología. Edición, volumen $17.4 \mathrm{http}: / / \mathrm{www} \cdot$ asoneumocito. org/upload/Vol-17-4-4_g.pdf

13. Tobón A, Agudelo C, Rosero D, Ochoa J, Bedout C, Zuluaga C, Arango M, et al. (2005). Disseminated histoplasmosis: a comparative study between patients with acquired immunodeficiency syndrome and non-human immunodeficiency virus-infected individuals. Am J Trop Med Hyg, 73:576-582 http:/ / www.ajtmh.org/content/73/3/576.full

14. Arango M, Castañeda E, Agudelo CI, De Bedout C, Agudelo CA, et al. (2011). Histoplasmosis: results of the Colombian National Survey, 1992-2008. Biomédica. 31(3). http:// www.revistabiomedica.org/index.php/ biomedica/article/view/348

15. Muñoz C, Cano L, González A. (2010). Detección e identificación de histoplasma capsulatum por el laboratorio: de los métodos convencionales a las pruebas moleculares. Infectio, 14(S2):S145-S158. http:// revistainfectio.org/site/portals/0/ojs/ index.php/infectio/article/view / 26

16. J Wheat. (2007). Clinical practice guidelines for the management of patients with histoplasmosis: 2007 update by the infectious diseases society of America. Clin Infect Dis, 45(7): 807-825. http://www.uphs.upenn. edu/ bugdrug/antibiotic_manual/historx. pdf 